\title{
Construções correlatas aditivas e disjuntivas
}

\section{Additive and disjunctive correlative constructions}

Ivo da Costa do Rosário

rosario.ivo3@gmail.com

Universidade Federal Fluminense

RESUMO: Este artigo visa a discutir o estatuto da correlação e o papel dos correlatores no âmbito das construções aditivas e disjuntivas do português. A tradição gramatical defende a visão dicotômica de que só há dois processos de ligação de sentenças: a subordinação e a coordenação. No campo da coordenação, as aditivas e as alternativas são normalmente reunidas em um mesmo grupo, sem a devida atenção para suas especificidades. A partir do instrumental teórico da Linguística Funcional Centrada no Uso, por meio de uma pesquisa baseada em dados reais de língua escrita formal contemporânea, o artigo demonstra as diferenças entre aditivas coordenadas e aditivas correlatas, bem como entre alternativas coordenadas e disjuntivas correlatas.

PALAVRAS-CHAVE: Correlação. Adição. Disjunção.

ABSTRACT: This article aims to discuss the correlation status and the role correlators play in the scope of additive and disjunctive constructions of Portuguese. The grammatical tradition defends the dichotomous view that there are only two connection processes of sentences: subordination and coordination. In the field of coordination, the additive and alternative clauses are usually gathered in the same group, without any attention to their specificities. In the theoretical basis of UsageCentered Functional Linguistics, through a research based on real data of contemporary formal written language, the article demonstrates the differences between additive coordinated clauses and additive correlative clauses, as well as between alternative coordinated clauses and disjunctive correlative clauses. KEYWORDS: Correlation. Addition. Disjunction.

Professor Adjunto do Instituto de Letras e do Programa de Pós-graduação em Estudos de Linguagem da Universidade Federal Fluminense. 


\section{Considerações iniciais}

Uma rápida consulta aos principais compêndios gramaticais produzidos no Brasil revela, nas páginas destinadas à sintaxe do período composto, que há apenas dois grandes processos de conexão de orações: a subordinação e a coordenação. Esse tipo de informação, por sua vez, é propagado nas escolas brasileiras desde o ensino fundamental, que é a primeira etapa da escolarização básica, até níveis mais avançados de ensino.

A questão é que um exame mais aprofundado da estrutura da língua portuguesa revela que essa proposta é, no mínimo, inconsistente e incompleta. Afinal, há pelo menos mais dois recursos utilizados pelos falantes e escreventes para a conexão de orações: a justaposição e a correlação, ambos preteridos pela onda estruturalista dicotomizadora da NGB (cf. Rosário, 2007, 2009, 2011, 2012, 2013, 2014, 2015, 2016).

Dentro da grande complexidade que caracteriza o processo de correlação, neste artigo, visamos a traçar um panorama que focaliza dois tipos distintos de correlação: a correlação aditiva e a correlação disjuntiva ${ }^{1}$. Esse recorte se dá em razão de esses dois tipos de correlação estarem normalmente inseridos, nas obras tradicionais, nos capítulos destinados à discussão da coordenação. Para fins ilustrativos, vejamos um dado de cada:

(01) Somos, às vezes, interlocutores não apenas de reivindicações, mas somos uma espécie de interlocutores dispostos a ouvir todo sofrimento das pessoas, toda natureza de sofrimento ${ }^{2}$.

(02) Sabe-se que a capacidade de aceitação pela sociedade de situações absurdas tem limites: ou a Argentina passa a levar em consideração tal aspecto ou não sai do lugar $^{3}$.

Tanto em (01) quanto em (02), há construções instanciadas por correlatores, ou seja, pares descontínuos de conectivos (não apenas... mas; ou... ou). Na

\footnotetext{
${ }^{1}$ Optamos por denominar as chamadas correlatas alternativas de correlatas disjuntivas. Apesar de o termo disjunção ser utilizado na literatura tanto para fazer referência a estruturas coordenadas quanto a estruturas correlatas, consideramos que é pertinente marcar cada um dos processos por meio de termos diferentes.

${ }^{2}$ Dado extraído de $h$ ttp://www.aleri.ri.gov.br. Vide seção 1 para mais informações.

${ }^{3}$ Dado extraído de http://www.veja.abril.com.br. Vide seção 1 para mais informações.
} 
correlação, a prótase (primeira parte da construção) sempre acarreta uma apódose (segunda parte da correlação). Entre ambas essas partes, estabelece-se uma relação de interdependência, com implicações semântico-pragmáticas que serão discutidas adiante. Essas primeiras observações, por si sós, já justificam um estudo mais aprofundado dessas construções, pois elas diferem, de forma flagrante, respectivamente, das coordenadas aditivas instanciadas por e e das coordenadas alternativas instanciadas por um simples ou. Essa é a hipótese a ser defendida neste trabalho.

Ainda há outras construções correlatas a serem investigadas de forma mais profunda, como a proporcional, a consecutiva, a comparativa, a substitutiva, entre outras. Esse é um empreendimento a ser alcançado em longo prazo, a partir de uma rede de pesquisas que vem sendo desenvolvida no âmbito do Grupo de Pesquisa Conectivos e Conexão de Orações (CCO) e também em outros centros de investigação no país.

O instrumental teórico que embasa este estudo é a Linguística Funcional Centrada no Uso, doravante denominada LFCU. O objetivo central dessa corrente é desenvolver investigações baseadas em corpora de língua real, tanto na modalidade falada quanto na escrita. Neste artigo, o recorte é de base sincrônica e toma como ponto de partida a análise da língua padrão, consignada em duas fontes distintas: o site da Assembleia Legislativa do Estado do Rio de Janeiro (para o caso das aditivas) e o site da Revista Veja On Line (para o caso das disjuntivas).

$\mathrm{Na}$ seção 1, apresentamos brevemente a corrente teórica que ancora as discussões que são desenvolvidas neste artigo, ou seja, a LFCU. De forma bastante breve, apresentamos os seus pressupostos teórico-metodológicos. $\mathrm{Na}$ seção 2 , caracterizamos o processo de coordenação a partir de diferentes vertentes teóricas. Em seguida, na seção 3, analisamos a correlação aditiva. $\mathrm{Na}$ seção 4, apresentamos a correlação disjuntiva. Por fim, tecemos algumas considerações finais e apresentamos as referências bibliográficas.

\section{LFCU - pressupostos teórico-metodológicos}

A LFCU é uma corrente que amalgama pressupostos teóricos advindos tanto do Funcionalismo quanto do Cognitivismo. Nesse modelo, destacam-se as 
contribuições da Gramática de Construções, em especial a partir dos modelos desenvolvidos por Langacker (2008), Goldberg (1995, 2003) e Croft (2001). Rosário e Oliveira (2016, p. 236) abordam essa questão:

$\mathrm{Na}$ contemporaneidade, o Funcionalismo de vertente norteamericana amplia seu espectro de observação e incorpora, de modo mais efetivo, a dimensão contextual. Nesse sentido, destaca-se a abordagem holística e contingencial dos usos linguísticos, na consideração de que itens não ocorrem ou produzem sentido isoladamente, de que é preciso considerar as relações contextuais. Tal reorientação corresponde ao Funcionalismo na contemporaneidade e concebe a estrutura linguística como derivada de processos cognitivos gerais, de acordo com Bybee (2010). Os usos linguísticos são, nesse âmbito, entendidos como produto da experiência, da rotinização e da perspectivização na e pela linguagem, entre outras motivações.

Como fica claro, a LFCU é mais abrangente ao considerar questões cotextuais, contextuais e discursivas de modo geral (cf. CEZARIO, CUNHA, 2013). Ademais, a contribuição do Cognitivismo é decisiva no sentido de aprimorar a análise de aspectos ligados a perspectivização e expressão da experiência.

No Funcionalismo clássico, havia um foco bastante concentrado nos itens gramaticais, de modo que os estudos em gramaticalização normalmente estavam baseados em itens que migravam do léxico para a gramática (cf. ROSÁRIO, 2010a, 2010b, 2015). A consideração acerca de outros fatores não estava tão evidente no cenário das pesquisas. Esse é, sem dúvida, um avanço proporcionado pela LFCU.

Como assertam Traugott e Trousdale (2013, p. 32), o paradigma da gramaticalização, bastante utilizado no quadro teórico do Funcionalismo Clássico, basicamente referia-se a dois modelos: o da gramaticalização como redução, com foco em aspectos mortossintáticos; e o da gramaticalização como expansão, com foco em aspectos semântico-pragmáticos.

A LFCU, por sua vez, promove uma visão mais integradora ao considerar os diversos níveis de análise. O modelo de Croft (2001, p. 18), nesse sentido, tem sido bastante utilizado, tendo em vista a sua abrangência (cf. Figura 1).

Nesse modelo, forma e significado são pareados e considerados como igualmente relevantes na descrição linguística. Com relação aos aspectos formais, destacam-se as propriedades sintáticas, morfológicas e fonológicas. Com relação ao plano do sentido, apresentam-se as propriedades semânticas, pragmáticas e 
discursivo-funcionais. Assim, o esforço do pesquisador filiado à LFCU consiste em desvelar essas seis propriedades a partir das construções que se analisam.

Se há formação de uma nova construção, ou seja, um novo pareamento de forma e significado, então falamos em construcionalização. Por outro lado, se há mudança de apenas uma das propriedades anteriormente elencadas (ou no plano da forma ou no plano do sentido), então falamos em mudança construcional, sem criação de um novo nó da rede linguística.

Figura 1: Modelo de construção (Adaptado de Croft 2001)

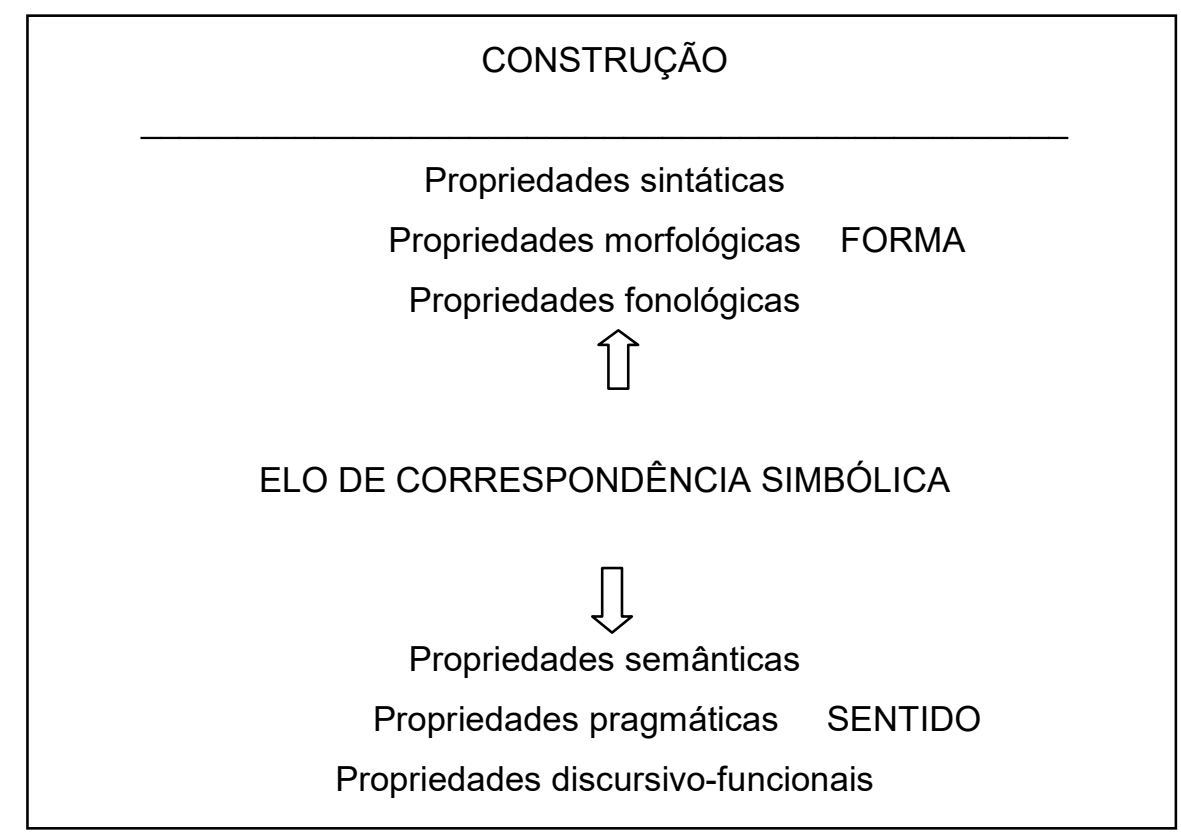

Nesse corpo teórico da LFCU, três fatores ganham especial destaque: a esquematicidade, a composicionalidade e a produtividade (cf. Traugott; Trousdale, 2013 , p. 113). Por esquematicidade, entendemos as generalizações taxonômicas que apontam para diferentes padrões rotinizados da experiência. Assim, a esquematicidade se apresenta $\mathrm{m}$ diferentes graus ou níveis: esquemas, subesquemas e microconstruções. Esses níveis expressam diferentes graus de abstratização. A composicionalidade está associada ao grau de transparência entre forma e significado das diversas construções. Se uma construção é bastante composicional, isso significa que há grande transparência entre os elementos que a compõem e baixa opacidade. Por fim, a produtividade relaciona-se ao grau em que os esquemas sancionam ou restringem construções mais ou menos esquemáticas. 
Esse conceito associa-se com o de frequência, que pode ser de tipo (frequência type) ou de ocorrência (frequência token).

Por fim, dois conceitos basilares na LFCU são os seguintes: neoanálise e analogização. A neoanálise, na visão de Traugott e Trousdale (2013), consiste nos pequenos passos atestados em uma mudança construcional. Ao longo do tempo, vem sendo estendida de um viés estritamente morfossintático para uma perspectiva semântica. Como a visão de mudança defendida pela LFCU é gradual, a neonálise revela-se com forte potencial descritivo.

A analogização, por sua vez, consiste na atração de novas formas e/ou novas funções a exemplares já existentes. É concebida como um mecanismo de mudança, pois promove novos alinhamentos na língua a partir de padrões já estabilizados.

O pesquisador que adota a LFCU essencialmente trabalha a partir de dados, pois é o uso o verdadeiro motor da mudança linguística (cf. Cezario; Cunha, 2013; Traugott; Trousdale, 2013; Rosário; Oliveira, 2016). Nesse sentido, a definição de um corpus de língua real (na modalidade falada ou escrita) passa a ser fundamental nesse enquadre. Este artigo parte de dois corpora para a investigação que está sendo proposta.

A análise das correlatas aditivas toma como base o site eletrônico http://www.alerj.rj.gov.br, que apresenta os discursos políticos dos deputados da Assembleia Legislativa do Estado do Rio de Janeiro, nos últimos anos. A investigação da correlação disjuntiva, por sua vez, toma como base o acervo digital da Revista Veja on-line, que se encontra disponível em http://www.veja.abril.com.br.

A amostra recortada para a análise representa um conjunto de textos de base sincrônica, que espelha os usos contemporâneos da língua portuguesa no século XXI. A escolha dos corpora indicados se dá em função da alta carga argumentativa dos textos, que costuma ser o locus da correlação (cf. ROSÁRIO, 2012). Esses são os principais pressupostos teórico-metodológicos que balizam a análise empreendida neste artigo.

\section{0 processo de coordenação}

Os autores tradicionais, via de regra, estabelecem que a coordenação implica uma relação de independência entre orações. Para alguns, essa independência é de 
natureza gramatical ou sintática; para outros, é de natureza semântica. Ambos os pontos de vista são discutíveis, ainda mais quando as obras normativas abrigam estruturas correlatas no bojo da coordenação.

Rosário (2016, p. 254; grifos do autor), após amplo estudo das obras tradicionais, detectou o seguinte:

Para Rocha Lima (1999) e Ribeiro (2004) [...], a subordinação exibe uma relação de dependência sintática. Para Almeida (2004) e Bueno (1963), por outro lado, trata-se de uma relação de dependência semântica. Da mesma forma como há divergência no tocante à subordinação, também há dissensões no âmbito da coordenação. Assim, para Cunha e Cintra (2001) e Kury (2003), na coordenação, há independência semântica. Já para Rocha Lima (1999) e Ribeiro (2004), trata-se de um caso de independência sintática.

Como comprova o autor, a questão do critério da (in)dependência é bastante frágil, tendo em vista que é tomado de forma muito distinta por parte dos autores em geral. Givón (1990, p. 826) ilumina esse ponto de vista ao propor que a total independência é algo impossível no âmbito da ligação de orações e períodos, visto que, em geral, todos os textos apresentam conexões, o que invariavelmente nos leva à conclusão de que não há independência absoluta entre orações.

Em outras palavras, há sempre algum nível de dependência entre as orações, pelo menos semântico-pragmática, em maior ou menor grau, conforme intuíram alguns autores até mesmo na Tradição (cf. Rosário, 2016, p. 265). Seria mais acertado falarmos, portanto, em graus de dependência e integração, em vez de adotarmos posturas rígidas de categorização.

Em obra clássica sobre o Funcionalismo de vertente norte-americana, Hopper e Traugott (1997, p. 170-171) propõem o seguinte continuum:

Quadro 1: Dependência e encaixamento

\begin{tabular}{|c|c|c|c|}
\cline { 2 - 4 } \multicolumn{1}{c|}{} & $\begin{array}{c}\text { Parataxe } \\
\text { (independência) }\end{array}$ & $\begin{array}{c}>\text { Hipotaxe } \\
\text { (interdependência) }\end{array}$ & $\begin{array}{c}>\text { Subordinação } \\
\text { (dependência) }\end{array}$ \\
\hline [Dependência] & - & + & + \\
\hline [Encaixamento] & - & - & + \\
\hline
\end{tabular}


Na perspectiva dos autores, é preciso adotar uma visão escalar dos conceitos de dependência e encaixamento. Com relação à parataxe, que no momento é mais central para a discussão aqui desenvolvida, Hopper e Traugott (1997) afirmam que há [- dependência] e [- encaixamento]. Deve ficar claro que essa perspectiva é distinta das tradicionais, visto que os autores conjugam aspectos sintáticos e semânticos e admitem uma visão escalar, em que a coordenação teria menos dependência (e não independência total). Assim, rompem com visões dicotômicas e categóricas.

Raposo et al (2013, p. 1760) afirmam o seguinte com relação à coordenação:

A coordenação integra-se na classe mais vasta dos processos paratáticos (mais simplesmente, parataxe), caracterizados por combinarem unidades gramaticalmente idênticas ou semelhantes, por vezes em qualquer articulação formal, de tal maneira que, no constituinte resultante, as duas unidades são equivalentes, encontrando-se no mesmo nível hierárquico da estrutura sintática.

A definição apresentada por Raposo et al (2013) permite uma importante conclusão acerca da coordenação: esse processo gera "unidades gramaticalmente idênticas ou semelhantes". Em outras palavras, estabelece-se uma relação de coigualdade sem qualquer tipo de hierarquização. Assim, qualquer "desnível" de uma parte da coordenação em relação à outra seria algo estranho a esse processo. Afinal, nenhum dos elementos coordenados apresenta proeminência estrutural sobre o outro (RAPOSO et al, 2013, p. 1761).

Essa definição apresentada pelos autores é bastante compatível com a preconizada por Ramat e Mauri (2011, p. 654), no quadro de uma perspectiva translinguística. Segundo os autores, as propriedades da coordenação são bem distintas entre as línguas, e as marcas dessa relação exibem diferentes graus de gramaticalização, mas, em geral, uma relação de coordenação é aquela que se estabelece entre dois estados de coisas funcionalmente equivalentes, com a mesma função semântica.

Matos (2013, p. 551) também segue uma linha semelhante à de Raposo et al e de Ramat e Mauri (2001) ao afirmar que a coordenação é um processo de formação de unidades complexas e que se caracteriza "por combinar constituintes do mesmo nível categorial - [...] sintagmas ou frases - que desempenham as mesmas funções sintáticas e semânticas". Por outro lado, a autora é bastante 
prudente ao afirmar que essa caracterização aplica-se apenas aos casos mais canônicos de coordenação.

Essa breve inserção no campo dos estudos linguísticos dedicados à investigação da conexão de orações permite a conclusão de que o conceito de coordenação implica coigualdade, não hierarquização, paralelismo sintático (e/ou semântico), semelhança entre os termos ligados. Esses traços estão presentes na maioria das descrições, desde obras mais tradicionais até obras mais inovadoras.

A dedução lógica de tudo o que vimos apresentando é que, se as correlatas aditivas e correlatas disjuntivas são casos de coordenação, como é apresentado pela ampla maioria dos autores tradicionais, logo, conclui-se que as propriedades associadas à coordenação necessariamente devem ser aplicadas aos casos de correlação. As duas seções seguintes visam a investigar essa questão, com base em dados de língua real.

\section{A correlação aditiva}

De uma forma geral, a noção de adição só surge nas gramáticas quando se fala nas orações coordenadas sindéticas aditivas. De forma indireta, esse tipo de abordagem pode fazer o leitor pressupor que a adição só operaria no processo de coordenação e no plano da integração de orações (e não no plano dos sintagmas, por exemplo). Afinal, quanto a outras formas de veiculação da ideia de adição, há um grande silêncio por parte dos autores.

Segundo Rosário (no prelo), é possível

uma sistematização das construções aditivas em um continuum de crescente integração e dependência. Assim, defendemos que nem todas as estruturas aditivas são estruturas de coordenação. Ao contrário, as diferentes construções estendem-se em um espectro que vai da justaposição paratática até a hipotaxe aditiva (introduzidas por além de).

De fato, as estratégias de veiculação da ideia de adição em português são múltiplas. No âmbito da correlação, por exemplo, segundo Rosário (2012, p. 128), a adição é instanciada por meio de, pelo menos, vinte e oito padrões construcionais distintos, com diferentes níveis de produtividade. Vejamos: 
Quadro 2: Padrões correlativos aditivos

\begin{tabular}{|c|c|}
\hline $\begin{array}{c}\text { PADRÃO } \\
\text { CONSTRUCIONAL }\end{array}$ & $\begin{array}{c}\text { PARES } \\
\text { CORRELATIVOS }\end{array}$ \\
\hline 1. & Não [V] apenas...mas \\
\hline 2. & Não [V] só...mas \\
\hline 3. & Não [V] só.... $\Delta^{4}$ \\
\hline 4. & Não [V] só...mas também \\
\hline 5. & Não [V] apenas...mas [V] também \\
\hline 6. & Não [V] só...como também \\
\hline 7. & Não [V] apenas.... \\
\hline 8. & Não só...como \\
\hline 9. & Não apenas...como [V] também \\
\hline 10. & $\Delta \ldots$ mas $[\mathrm{V}]$ também \\
\hline 11. & Não [ V ]somente.... \\
\hline 12. & Não [V] somente...mas também \\
\hline 13. & Não [V] somente...mas \\
\hline 14. & $\Delta \ldots$...como também \\
\hline 15. & Não [V] só...também \\
\hline 16. & Não somente...como também \\
\hline 17. & Não apenas...como \\
\hline 18. & Não só...e sim \\
\hline 19. & Não [V] apenas...e sim \\
\hline 20. & Não...mas também \\
\hline 21. & Não [V] só....mas sim \\
\hline 22. & Não simplesmente...mas \\
\hline 23. & Não simplesmente.... \\
\hline 24. & Não somente...mas como \\
\hline 25. & Não [V] somente...também \\
\hline 26. & Não apenas...também \\
\hline 27. & Não só...e também \\
\hline 28. & Não somente...e sim \\
\hline
\end{tabular}

Essa diversidade de formas utilizadas para a expressão da adição correlativa definitivamente não está a serviço do mesmo papel desempenhado pela

\footnotetext{
${ }^{4}$ Segundo Rosário (2012), o símbolo $\Delta$ indica que o segundo correlator não é instanciado em termos formais.
} 
coordenação aditiva. São estratégias distintas tanto no plano morfossintático quanto semântico-pragmático. Cumprem diferentes funções no discurso e apresentam traços formais também distintos. A título de exemplificação, vejamos o dado abaixo:

(03) As coisas vão surgindo e eu venho a esta tribuna, não só para esta denúncia e também essa reivindicação, como também para alertar o Governo do Estado sobre o Plano de Cargos, Carreiras e Salários dos profissionais de Saúde.

Esse mesmo dado pode ser esquematizado da seguinte forma:

Esquema 1: Correlação em nível inferior e superior à coordenação

\begin{tabular}{|c|c|c|}
\hline \multirow{4}{*}{$\begin{array}{c}\text { As coisas vão } \\
\text { surgindo }\end{array}$} & não só para esta denúncia & $\begin{array}{c}|c| \\
\text { como também para alertar o } \\
\text { e também essa } \\
\text { reivindicação }\end{array}$ \\
\cline { 2 - 3 } & $\begin{array}{c}\text { Governo do Estado sobre o Plano de } \\
\text { Cargos, Carreiras e Salários dos } \\
\text { profissionais da Saúde }\end{array}$ \\
\cline { 2 - 3 } & Prótase correlativa & Apódose correlativa \\
\hline
\end{tabular}

Nesse dado (03), o e é utilizado em dois diferentes níveis: acima da correlação ("e eu venho a esta tribuna") e abaixo da correlação ("e também essa reivindicação"). Esse último uso de e está "dentro" da prótase correlativa.

A análise atenta desse dado mostra que coordenação aditiva e correlação aditiva ocupam "lugares" diferentes no plano discursivo e cumprem funções distintas no plano argumentativo. A primeira coordenada aditiva é uma grande estrutura complexa que une o segmento "As coisas vão surgindo" ao restante de toda informação dada. Dentro do segundo membro coordenado, há uma correlação que, por sua vez, une duas informações: a) $O$ deputado vai à tribuna para fazer uma denúncia e uma reivindicação; b) O deputado alerta o Governo do Estado sobre o Plano de Cargos, Carreiras e Salários dos profissionais da saúde.

A correlação aditiva é utilizada para unir essas informações $a$ e $b$ porque não se dá, de fato, uma simples união ou aproximação de ideias, como é comum na coordenação aditiva. Não se estabelece uma relação de coigualdade (LANGACKER, 2008), nem há relação de independência sintático-semântica entre ambas as informações. $\mathrm{O}$ que se verifica, de fato, é um crescendum argumentativo em que 
uma informação mais previsível e menos relevante é posta em primeiro lugar (na prótase) para, em seguida, uma informação mais imprevisível, mais relevante e mais nova ser posta em segundo lugar (na apódose).

Segundo Croft (2001, p. 340),

A prótase (inicial) funciona como o tópico para o apódose; ela expressa conhecimento comum, que serve como um quadro para o material seguinte [...] Isso se assemelha ao princípio gestáltico da dependência funcional, que é usado para distinguir figura e fundo.

Uma simples coordenação aditiva instanciada por e não seria capaz de espelhar esse arranjo sintático-semântico proporcionado pela correlação aditiva em (03). Assim, as motivações pragmático-discursivas da correlação aditiva, de fato, não se confundem com o papel do conectivo e em língua portuguesa.

A correlação e a coordenação foram estratégias utilizadas pelo falante em uma mesma porção textual, mas com objetivos comunicativos distintos, visando a expressar conteúdos semântico-pragmáticos também distintos. $\mathrm{Na}$ correlação aditiva, uma informação já dada ou menos relevante projeta uma informação nova ou mais relevante, causando o que chamamos de crescendum argumentativo. Gervásio (2016, p. 74) ilustrou esse arranjo da seguinte forma:

Figura 2: Prótase e apódose (adaptado)

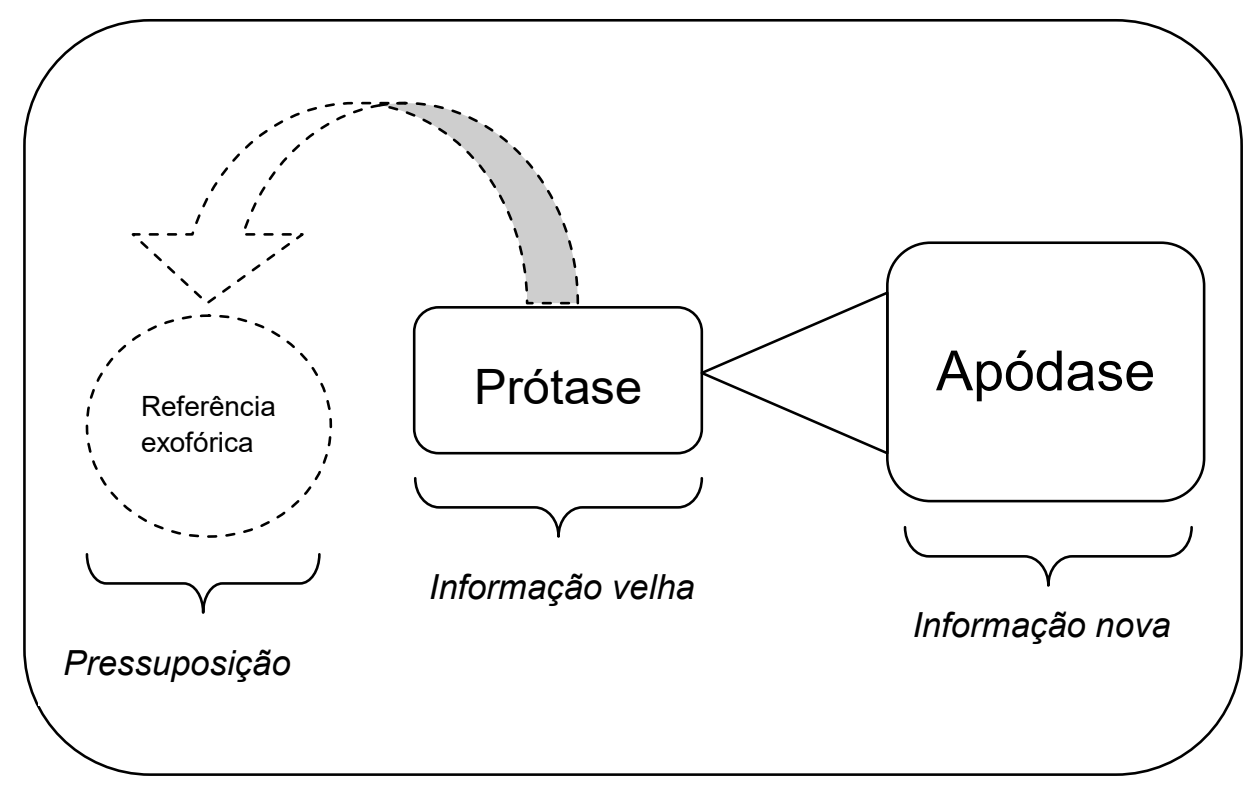

Pela figura anterior, é possível verificar que a prótase faz referência a algo pressuposto, por meio de uma referência exofórica. A apódose (ou apódase), por 
sua vez, é projetada a partir da prótase, criando-se um laço de interdependência entre ambas as partes. Esse arranjo é bastante distinto do que se verifica em uma coordenação aditiva prototípica, como é ilustrado por Langacker (2008, p. 410):

Figura 3: Coordenação (adapatado de Langacker, 2008)

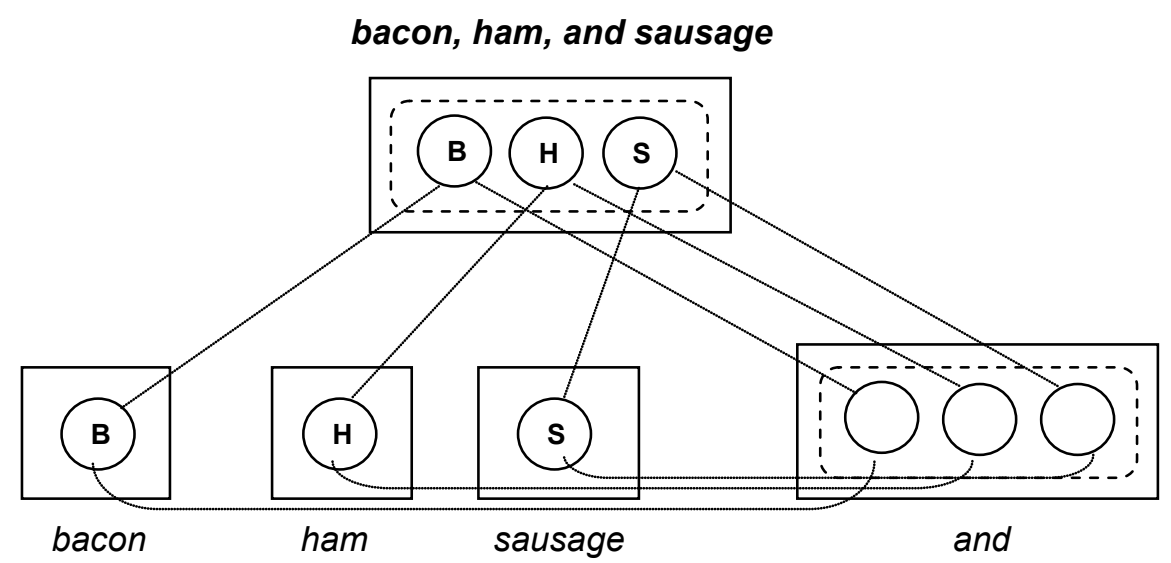

Segundo Langacker (2008, p. 410), a coordenação aditiva prototípica institui uma relação de coigualdade, o que é retratado pela disposição dos elementos anteriores (bacon - ham - sausage) em um mesmo nível horizontal e com um mesmo peso, sem hierarquização. De fato, a coordenação aditiva stricto sensu produz uma combinação bastante fundamental e mínima, bastante semelhante a um processo de justaposição.

Concordamos com Givón (1990, p. 343), quando o autor afirma:

A gramática da combinação de orações no discurso conectado, marcando diferentes graus de dependência sintática interoracional, não é senão a reflexão sistemática do grau em que dois eventos (ou estados) são enquadrados em conjunto [framed jointly] a partir da perspectiva da cognição ou comunicação.

Essa afirmação de Givón (1990) revela que as diferentes formas de expressão carreiam diferentes enquadramentos ou perspectivas sobre cenas e atividades. Em obra posterior, Goldberg (1995, p. 67-68) lança um corolário que, em outras palavras, reelabora o pensamento givoniano. Esse corolário, conhecido como princípio da não sinonímia da forma gramatical, indica que, se duas construções são sintaticamente distintas, elas devem ser semântica ou pragmaticamente distintas. Trazendo essas reflexões para o âmbito do período composto, é possível defender 
que os diferentes graus de dependência sintática estão estreitamente relacionados a diferentes semânticas. Assim, coordenadas aditivas são distintas de correlatas aditivas nos planos morfossintático, semântico, pragmático e discursivo.

A fim de ilustrar ainda mais as diferenças entre ambos os processos, Rosário (2012, p. 219), com base em outros autores, cotejou algumas propriedades da correlação aditiva e da coordenação aditiva. Vejamos:

Quadro 3: Diferenças entre correlação aditiva e coordenação aditiva

\begin{tabular}{|c|c|}
\hline Correlação aditiva & Coordenação aditiva \\
\hline $\begin{array}{l}\text { Posição menos fixa dos correlatores. } \\
\text { (Heine et al., 1991, p. 15-16) }\end{array}$ & Posição mais fixa dos coordenadores \\
\hline $\begin{array}{c}\text { Maior escopo ou peso } \\
\text { (Heine et al., 1991, p. 15-16) }\end{array}$ & $\begin{array}{c}\text { Menor escopo, o que significa o avanço } \\
\text { no processo de gramaticalização. }\end{array}$ \\
\hline $\begin{array}{l}\text { Conectores com maior quantidade de } \\
\text { massa fônica, ou seja, de substância } \\
\text { fonética. Tendem a ser polissilábicos } \\
\text { (Heine, 2003, p. } 579 \text {; Lehmann, 1985) }\end{array}$ & $\begin{array}{c}\text { Conectores mais reduzidos } \\
\text { foneticamente, tendo em vista a } \\
\text { prototípica conjunção coordenativa } \underline{e} \text {. } \\
\text { Tendência à ocorrência de conectores } \\
\text { monossilábicos. }\end{array}$ \\
\hline $\begin{array}{l}\text { Apresenta menor distribuição, ou seja, } \\
\text { menor frequência de uso ou habituação } \\
\text { (Bybee; Pagliuca, 1985, p. 63) }\end{array}$ & $\begin{array}{l}\text { Apresentam maior frequência de uso, ou } \\
\text { seja, maior generalização contextual, se } \\
\text { comparada à correlação }\end{array}$ \\
\hline $\begin{array}{c}\text { Grande profusão de padrões responsáveis } \\
\text { por ligar os elementos correlatos, ou seja, } \\
\text { maior competição de formas. } \\
\text { (Heine et al, 1991, p. 15-16; Lehmann, } \\
1985)\end{array}$ & $\begin{array}{l}\text { Maior redução no número de membros } \\
\text { pertencentes ao mesmo paradigma } \\
\text { morfossintático, haja vista a } \\
\text { prototipicidade do conectivo } \underline{e} \text {. }\end{array}$ \\
\hline Itens mais formais (Votre et al, 2004, p. 77) & Itens mais informais \\
\hline $\begin{array}{l}\text { Sempre marcada pela síndese } \\
\text { (Lehmann, 1985) }\end{array}$ & $\begin{array}{l}\text { Pode ser marcada por assíndese, haja } \\
\text { vista a parataxe justaposta. }\end{array}$ \\
\hline $\begin{array}{c}\text { Menor desbotamento, tendo em vista a } \\
\text { manutenção da ideia de adição como } \\
\text { prevalente. }\end{array}$ & $\begin{array}{c}\text { Maior dessemanticização, tendo em } \\
\text { vista usos menos verifuncionais. (Heine, } \\
\text { 2003) }\end{array}$ \\
\hline $\begin{array}{l}\text { Quanto aos correlatores, maior perda de } \\
\text { significação pragmática e mais ganho em } \\
\text { termos de significação sintática. } \\
\text { (Heine et al, 1991, p. 15-16 }\end{array}$ & $\begin{array}{c}\text { Conectores já altamente } \\
\text { gramaticalizados pela intensidade de } \\
\text { uso. }\end{array}$ \\
\hline
\end{tabular}


As reflexões apresentadas nesta seção 3 permitem confirmar a hipótese de que a coordenação aditiva, de fato, é distinta da correlação aditiva, tanto nos planos formal quanto funcional. Vejamos agora a correlação disjuntiva.

\section{A correlação disjuntiva}

Assim como acontece com as correlatas aditivas, também as correlatas disjuntivas costumeiramente são alocadas no campo da coordenação, sem uma distinção necessária entre estruturas coordenadas de fato e estruturas correlatas.

A título de ilustração, Rocha Lima (1999, p. 185), por exemplo, afirma que as conjunções alternativas relacionam pensamentos que se excluem, e acrescenta: "o tipo é ou, que pode repetir-se, ou não, antes de todos os elementos coordenados. Além dela, indicam alternação: ou...ou, ora...ora, seja...seja, quer...quer, já...já".

De forma indireta e velada, a reflexão do gramático permite a conclusão de que a escolha, por exemplo, de uma conjunção simples (ou) ou uma conjunção descontínua (ou...ou) seria meramente de base pessoal ou estilística, tendo em vista que seriam equivalentes do ponto de vista semântico-pragmático. Isso é corroborado por Cunha e Cintra (2001, p. 580) quando afirmam que as orações alternativas são veiculadas por meio do uso de "conjunções alternativas ou (repetida ou não) e, quando repetidas: ora...ora, quer...quer, etc."

Defendemos que há diferenças entre as distintas possibilidades de expressão da ideia de alternância ou disjunção. Vejamos dois dados abaixo:

(04) Ótima reportagem da jornalista Tatiana Gianini ("O México pronto para decolar, 3 de abril). Ou cultivamos as eternas virtudes do livre mercado ou optamos pelo estatismo fanático e afundamos no lamaçal boliviano, com a Venezuela e a Argentina.

(05) A boa vontade com o Brasil é imensa. Somos um país pacífico, unificado pelo idioma sem disputas étnicas ou religiosas, com uma população que começa a ter oportunidades iguais de educação e ascensão social.

Segundo Acosta (2016, p. 37), embora (04) e (05) apresentem estruturas sintáticas semelhantes, visto que utilizam o conectivo ou como base, não são sinônimas. Em (04), o uso de correlatores (ou...ou) leva a informação a uma leitura exclusiva, ou seja, o cultivo das eternas virtudes do livre mercado necessariamente exclui a opção pelo estatismo fanático. Em (05), por sua vez, o uso de um único 
conectivo simples (ou) pode carrear tanto uma leitura exclusiva (ou disputas étnicas ou disputas religiosas) quanto inclusiva, de cunho aditivo (disputas étnicas e disputas religiosas). Neves (2000) reitera essa questão ao afirmar que as disjunções com ou ora podem indicar inclusão, ora exclusão, e que a disjunção com ou...ou sempre será exclusiva.

Raposo et al (2013, p. 1778), apesar de não reconhecerem a correlação como um processo autônomo em relação aos demais, também asseveram que construções com ou são diferentes das construções instanciadas por ou...ou:

Quanto a aparente exceção a este princípio da conjunção correlativa ou...ou, consideramos aqui que ou simples é uma conjunção distinta de ou...ou correlativo, não resultando, pois, de uma simplificação desta por omissão do primeiro elemento. A corroborar esta análise note-se que ou...ou tem preferencialmente uma leitura de disjunção exclusiva, ao passo que ou simples pode ser exclusivo ou inclusivo: assim, a interpretação mais natural da frase (exprimindo uma ordem) ou ouves música ou lês leva à inferência pelo ouvinte de que apenas umas das possibilidades são permitidas, algo que não acontece em ouves música ou lês, que pode ser seguido por faz o que te apetecer.

Mais uma vez evocamos o princípio da não sinonímia da forma gramatical. Se a língua apresenta duas formas diferentes de dizer algo, é porque uma forma apresenta algum traço semântico ou pragmático distinto das demais. Em outras palavras, em tese, não há duas formas com dois sentidos exatamente iguais. De fato, a constatação de uma diferença no plano morfossintático (presença de correlatores, ou seja, conectivos descontínuos) e uma diferença no plano semânticopragmático (a ideia sempre presente de disjunção exclusiva) reforçam a hipótese de que correlação disjuntiva cumpre um papel distinto da coordenação alternativa em língua portuguesa.

Acosta (2016) desenvolveu uma pesquisa empírica com base em dados de língua escrita formal. A pesquisadora aferiu os pares correlativos disjuntivos encontrados no corpus e verificou o seguinte:

Tabela 1: Correlatores disjuntivos

\begin{tabular}{|c|c|c|}
\hline TYPES & TOKENS & $\%$ \\
\hline ou...ou & 63 & $34,8 \%$ \\
\hline seja...seja & 42 & $23,2 \%$ \\
\hline seja...ou & 32 & $17.7 \%$ \\
\hline
\end{tabular}




\begin{tabular}{|c|c|c|}
\hline ora...ora & 21 & $11.6 \%$ \\
\hline nem...nem & 16 & $8,8 \%$ \\
\hline quer...quer & 4 & $2,2 \%$ \\
\hline quer...ou & 2 & $1,2 \%$ \\
\hline nem...ou & 1 & $0,5 \%$ \\
\hline TOTAL & 181 & $100 \%$ \\
\hline
\end{tabular}

Como se observa, os correlatores ou...ou foram os mais frequentes, com quase 35\% das ocorrências. Os quatro pares canônicos seguintes (seja...seja, ora...ora, nem...nem, quer...quer) normalmente apresentados pelos gramáticos também foram encontrados no corpus, com diferentes índices de produtividade.

A partir dessa tabela, três types (seja...ou, quer...ou e nem...ou) chamam a atenção pelo fato de não serem espelhados, ou seja, o primeiro correlator é distinto do segundo. Esses correlatores são poucos frequentes na linguagem padrão escrita e, provavelmente por conta disso, não estão apontados nas gramáticas normativas.

Pezatti e Longhin-Thomazi (2008, p.898), ao abordarem a relação de disjunção, fazem referência à correlação instanciada por seja...ou. As autoras afirmam que esse par, diferentemente do que "preveem as convenções normativas", apresenta duas conjunções distintas para estabelecer a ligação de prótase e apódose.

Carvalho (2011, p. 365) também tece alguns comentários sobre esse uso, mas sob outro ponto de vista, o da norma gramatical:

O falante é livre para escolher uma conjunção alternativa entre várias ao seu dispor. Uma vez escolhida, a conjunção deve manter-se a mesma até o fim do período composto. Evitem-se, portanto, construções como: 'Ele sairá quer você queira ou não (queira)'. Ele ficou triste seja porque você o ofendeu, ou porque não gostou do que você disse' (Na primeira ocorrência, ou deve ser substituído por quer: quer não queira; na segunda ocorrência, ou deve ser substituído por seja: seja porque não gostou. Em ambos os casos, a correção visa manter um princípio de paralelismo de construção).

Uma pesquisa baseada na língua em uso muitas vezes revela-nos essas surpresas. No âmbito da LFCU, Acosta (2016) hipotetizou que tais usos se devem ao efeito da analogização, que levou à emergência de novos correlatores (cf. Efeito da analogização sobre o par correlativo ou...ou em Acosta, 2016). 
A partir do par correlativo disjuntivo prototípico ou...ou, por força da analogização, o primeiro correlator deu lugar a outra partícula (seja, quer, nem), de caráter mais inovador, enquanto o segundo correlator se manteve (ou). Esse movimento gerou pares mais inovadores, não espelhados, do tipo seja...ou, quer...ou, nem...ou.

Todos os traços e características da correlação disjuntiva também permitem a defesa de que essa é uma estratégia distinta da coordenação alternativa. As diferenças residem tanto no plano morfossintático quanto no plano semânticopragmático-discursivo. Ademais, enquanto a coordenação alternativa conta basicamente com um único conectivo (a conjunção ou), a correlação disjuntiva, por sua vez, por força de neoanálises e analogizações, vem sofrendo expansão ao abrigar novos correlatores, em busca de progressivos graus de expressividade.

\section{Considerações Finais}

O estudo detido dos diversos conectivos em língua portuguesa tem revelado importantes descobertas acerca dos processos de conexão de orações. Como llari (2008, p. 842) já havia apontado, além do papel sintático-semântico de unir sentenças, os conectivos "desempenham o papel argumentativo de sinalizar a 'orientação' e o peso que essas mesmas sentenças detêm enquanto argumentos para as conclusões que são objeto de negociação verbal entre interlocutores".

Em outras palavras, a opção do falante ou escrevente pelo uso de conectivos coordenativos ou de correlatores não é fortuita. $O$ uso da coordenação ou da correlação revela opções organizacionais diferentes para o discurso, tendo a correlação forte papel argumentativo e hierarquizador (ROSÁRIO, 2012), o que é um elemento nem sempre presente na coordenação.

A expansão do domínio da correlação é algo comum tanto no âmbito da adição quanto no da disjunção. As opções disponíveis para a conexão são numerosas no que tange ao plano dos conectivos. Isso pode ser explicado devido ao desejo do falante por maior expressividade (cf. TRAUGOTT, TROUSDALE, 2013, p. 124). Segundo os autores, o intento de atrair a atenção do falante (ou leitor) e de ser socialmente bem-sucedido são forças que motivam a criação de novas formas para novos significados em língua portuguesa. Devemos acrescentar que esse movimento normalmente é atestado no Funcionalismo Clássico ao afirmar que o 
falante explora antigas formas para novas funções (cf. HEINE et al, 1991, p. 28). Segundo Traugott (2007, p. 357), não há formas totalmente novas, mas sempre reutilização de formas anteriores, exatamente como verificamos no caso da correlação aditiva e na correlação disjuntiva.

Além das diferenças atestada no quadro 3, é possível apontar algumas outras diferenças que se aplicam às correlatas aditivas e disjuntivas em relação às coordenadas aditivas e alternativas. Com relação às correlatas,

a) Há menor propensão à sua substituição por justaposição ou assíndese (PETERSON, 1999, p. 137; GILI Y GAYA, 1955, p. 246). Naturalmente essa substituição é mais natural no plano da coordenação, pois é nesse processo em que verifica uma maior relação de coigualdade.

b) Os correlatores podem iniciar orações ou períodos. Raramente isso ocorre com os conectivos coordenativos aditivos ou disjuntivos.

c) Pares correlativos tendem a tirar a linearidade da frase, a sucessão temporal da sentença (MÓDOLO, 2004, p. 141)

Como afirmou Oiticica (1952, p. 2), a correlação é uma grande "floresta inexplorada". Essa bela metáfora tem sido um elemento de constante motivação para mais pesquisas na área. De fato, um tema tão caro aos estudos morfossintáticos não pode ficar em segundo plano, sem pesquisas que desvelem seus traços e especificidades.

Este artigo buscou cumprir mais um passo na grande trajetória rumo à descrição da rede construcional de todo domínio da correlação em língua portuguesa. Certamente ainda há muito a ser testado, investigado e analisado. Entretanto, defendemos que, a partir do que já foi apresentado, é possível postular que aditivas correlatas não pertencem ao grupo da coordenação aditiva. Da mesma forma, também é possível a defesa de que disjuntivas correlatas igualmente não pertencem ao grupo da coordenação alternativa.

\section{Referências}

ACOSTA, Jovana Mauricio. Análise funcional das construções correlatas alternativas. Dissertação (Mestrado em Estudos de Linguagem) - Universidade Federal Fluminense, Niterói - RJ, 2016. 
CARVALHO, José Augusto. Gramática Superior da Língua Portuguesa. Brasília: Thessaurus, 2011.

CEZARIO, Maria Maura; CUNHA, Maria Angélica Furtado (Orgs.). Linguística Centrada no Uso: uma homenagem a Mario Martelotta. Rio de Janeiro: Mauad $\mathrm{x}$ FAPERJ, 2013.

CROFT, William. Radical Construction Grammar. syntactic theory in typological perspective. Oxford: The Oxford University Press, 2001.

CUNHA, Celso; CINTRA, Lindley. Nova Gramática do Português Contemporâneo. 3. ed. Rio de Janeiro: Nova Fronteira, 2001.

GERVÁSIO, Tharlles Lopes. A construção correlata aditiva nos séculos XIX e XX: uma proposta de análise centrada no uso. Dissertação (Mestrado em Estudos de Linguagem) - Universidade Federal Fluminense, Niterói - RJ, 2016.

GILI Y GAYA, Samuel. Curso superior de sintaxis española. Barcelona: Publicaciones y Ediciones Spes S.A., 1955.

GIVÓN, Talmy. Syntax: a functional typological introduction. Amsterdam: John Benjamins, 1990. v. 2.

GOLDBERG, Adele E. Constructions: A Construction Grammar Approach to Argument Structure. Chicago: The University of Chicago Press, 1995.

Constructions: a new theoretical approach to language. Trends in Cognitive Sciences, vol.7, n.5, p. 219-224, 2003.

HEINE, Bernd et al. Grammaticalization: A conceptual framework. Chicago: The University of Chicago Press, 1991.

HOPPER, Paul; TRAUGOTT, Elizabeth. Grammaticalization. Cambridge: Cambridge University Press, 1997.

ILARI, Rodolfo et al. As conjunções. In: ILARI, Rodolfo; NEVES, Maria Helena de Moura (Orgs.). Gramática do Português Culto Falado no Brasil. São Paulo: Unicamp, 2008, v. 2, p. 809-864.

LANGACKER, Ronald W. Complex Sentences. In:__. Cognitive Grammar: a basic introduction. Oxford: Oxford University Press, 2008, p. 406-453

MATOS, Gabriela. Estruturas de coordenação. In: MATEUS, Maria Helena M. et al. Gramática da Língua Portuguesa. Lisboa: Caminho, 2003.

MÓDOLO, Marcelo. Gramaticalização das conjunções correlativas no Português. 2004. Tese (Doutorado em Filologia e Língua Portuguesa), Universidade de São Paulo, São Paulo, 2004.

OITICICA, José. Teoria da Correlação. Rio de Janeiro: Organizações Simões, 1952. 
PETERSON, Peter G. Coordinators plus plus? Journal of Linguistics, v. 27, n. 2, p. 127-142, 1999.

PEZATTI, Erotilde Goreti; LONGUIN-THOMAZI, Sanderléia Roberta. As construções coordenadas. In: ILARI, Rodolfo; MOURA NEVES, Maria Helena (Org.) Gramática do Português Culto Falado no Brasil: vol. 2 - classes de palavras e processos de construção. Campinas, SP: Editora da UNICAMP, 2008, p. 865-936

RAMAT, Anna Giacalone; MAURI, Caterina. The grammaticalization of coordinating interclausal connectives. In: NARROG, Heiko; HEINE, Bernd. (Org.) The Oxford Handbook of Grammaticalization. Oxford: Oxford University Press, 2011, p.653-664.

RAPOSO, Eduardo Bozaglo Paiva et al. (Orgs.). Gramática do Português. Lisboa: Calouste Gulbenkian, 2013. vol. I e II.

ROCHA LIMA, Carlos Henrique. Gramática Normativa da Língua Portuguesa. Rio de Janeiro: José Olympio, 1999.

ROSÁRIO, Ivo da Costa. Teoria da Correlação revisitada. In: Anais da IX Semana Nacional de Estudos Filológicos e Linguísticos, 2007, São Gonçalo - RJ, 2007. Disponível em: <http://www.filologia.org.br/ixsenefil/anais/25.htm>. Acesso em: 20 nov. 2017.

Construções aditivas - uma análise funcional. In: OLIVEIRA, Mariangela Rios de; ROSÁRIO, Ivo da Costa. (Org.). Pesquisa em linguística funcional: convergências e divergências. Niterói, RJ: Leo Christiano Editorial, 2009, p. 52-62.

Funcionalismo em Linguística. Revista Via Litterae, Anápolis, GO, v. 2, n. 2, p. 435-450, 2010a. Disponível em: <http://www2.unucseh.ueg.br/vialitterae/assets /files/vl_v2_v2/9-1-Funcionalismo_em_linguistica-raizes_passadas_e_irradiacoesfuturas-IVO_C_ROSARIO.pdf >. Acesso em: 20 nov. 2017.

Gramaticalização - uma visão teórico-epistemológica. Revista Palimpsesto, Rio de Janeiro, n. 11, ano 9, p. 1-18, 2010b. Disponível em: <http://www.pgletras. uerj.br/palimpsesto/num11/dossie/palimpsesto11_dossie02.pdf>. Acesso em: 20 nov. 2017.

RODRIGUES, Violeta Virginia. Correlação na perspectiva funcionalista. In: Violeta Virginia Rodrigues. (Org.). Articulação de orações: pesquisa e ensino. Rio de Janeiro: UFRJ, 2010c, p. 31-47.

Construções aditivas coordenadas e correlatas. In: X Fórum de Estudos Linguísticos da UERJ, 2011, Rio de Janeiro. Anais do X Fórum de Estudos Linguísticos da UERJ. Rio de Janeiro: Dialogarts, 2011, p. 1040-1050. Disponível em: <http://www.dialogarts.uerj.br/arquivos/livro_forum.pdf>. Acesso em: 20 nov. 2017.

Construções correlatas aditivas em perspectiva funcional. Tese (Doutorado em Letras) - Universidade Federal Fluminense, Niterói - RJ, 2012. 
. Construções correlatas aditivas na perspectiva da Linguística Funcional Centrada no Uso. In: IV Seminário Internacional e XVII Seminário Nacional do Grupo de Estudos Discurso de Gramática, 2013, Natal - RN. Anais do IV Seminário Internacional do Grupo de Estudos Discurso \& Gramática e XVII Seminário Nacional do Grupo de Estudos Discurso \& Gramática - Teoria da gramaticalização e Gramática de construções. Natal - RN: Editora da UFRN, 2013, p. 26-41 Disponível em: $\quad<$ https://degnatal.files.wordpress.com/2015/04/teoria-da-gramaticalizac3a7c3a 3o-e-gramc3a1tica-de-construc3a7c3b5es.pdf>. Acesso em: 20 nov. 2017.

Correlação. In: VIANNA, Edila; DIAS, Nilza Barrozo. (Orgs.). Língua Portuguesa III. Rio de Janeiro: Fundação CECIERJ, 2014, v. 1, p. 109-124

Sintaxe Funcional. In: OTHERO, Gabriel de Ávila; KENEDY, Eduardo

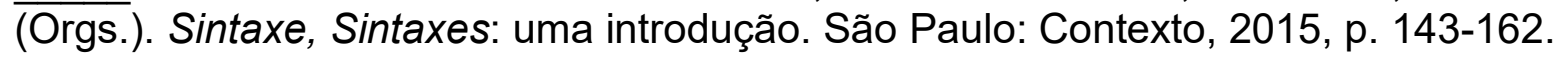

Reflexões sobre o critério da (in)dependência no âmbito da integração de orações. Revista Línguas \& Letras, Cascavel - PR, v. 17, n 35, p. 252-272, 2016. Disponível em: <http://e-revista.unioeste.br/index.php/linguaseletras/article/down load/12744/>. Acesso em: 20 nov. 2017.

. Construções correlatas aditivas são estruturas de coordenação? (no prelo)

; OLIVEIRA, Mariangela Rios. Funcionalismo e abordagem construcional da gramática. Revista Alfa, São Paulo, v. 2, n. 60, p. 233-259, 2016. Disponível em: <http://www.scielo.br/pdf/alfa/v60n2/1981-5794-alfa-60 -2-0233.pdf>. Acesso em: 20 nov. 2017.

TRAUGOTT, Elizabeth; TROUSDALE, Graeme. Constructionalization and constructional changes. Oxford: Oxford University Press, 2013. 